\title{
When are burns not accidental?
}

\author{
C J HOBBS
}

\author{
Department of Paediatrics and Child Health, St James's University Hospital, Leeds
}

SUMMARY One hundred and ninety five children aged up to 6 years with burns and scalds (30 non-accidental and 165 accidental) were studied retrospectively. The history, presentation, and other typical injuries assisted the diagnosis of abuse.

Scalds accounted for $81 \%$ of accidents and $25 \%$ of the cases of abuse, and burns for $17 \%$ and $44 \%$, respectively. Scalds usually followed spillage from kitchen containers in accidents and forced tap water immersion in cases of abuse. Burns in cases of both accidents and abuse resulted from contact with a wide range of household appliances, including room heaters.

Attention is drawn to the back of the hand as an important site in cases of abuse, as well as the legs, buttocks, and feet. It is speculated that the low level of reporting of this form of child abuse reflects failure of diagnosis.

Burns in young children arise in relation to three patterns of parental behaviour. Accidents result from lapses in the usual protection afforded to the child, neglect from inadequate or negligent parenting, and in cases of abuse the burn is deliberately inflicted, often as a form of punishment.

Earlier reports have suggested that $1-2 \%$ of children admitted to hospital in Britain with burns have sustained these as a result of non-accidental injury, ${ }^{12}$ although in other studies from the United States of America a higher incidence has been reported. ${ }^{3-5}$ Non-accidental burns are considered a serious form of child abuse because of the pain, anxiety, and morbidity accompanying this form of injury and in view of the element of premeditation in some cases.

The diagnosis of abuse in childhood burns remains difficult and unless other injuries, such as bruises or fractures, coexist may not be considered by the doctor. Diagnosis depends on awareness and the careful detection of clinical signs and discrepancies and inconsistencies in the history. This study provides guidelines that may assist in the recognition of non-accidental burns from an analysis of 195 children with burns, of whom 30 were abused.

\section{Patients and methods}

Children studied. One hundred and sixty five children with burns after accepted accidents were compared with 30 children with non-accidental burns. There were 109 boys ( 20 abused) and 87 girls (10 abused). Apart from one abused child aged 8, all were in the age range 5 months to 6 years.
Abuse. From January 1977 to June 1985 the Child Abuse Team in Leeds received referrals of 126 children suspected of abuse who had burns. Of these, 30 children had sustained 32 episodes of identified non-accidental injury, 51 children were judged to have been burned in genuine accidents, and 45 had received burns in uncertain or unsatisfactory circumstances, including many cases of neglect. The diagnosis of abuse was made by careful consideration of the pattern and type of burn in relation to the explanation offered. Additional injuries characteristic of abuse were found in 16 children, and in eight of these abuse was eventually admitted by one or other parent. There were two further children with non-organic failure to thrive and four children with isolated burns where the parent admitted abuse.

Finally, another two children convinced us that they had been deliberately burned by an adult. In the remaining six cases the diagnosis depended solely on discrepancies between the history and observed injury. Where serious doubt remained that abuse had occurred the case was not included in the study.

Accidents. One hundred and sixty five children consecutively admitted to St James's University Hospital in Leeds with accepted accidental burns and scalds were identified over a five year period. For every burn, as with the cases of abuse, the type, site, extent (expressed as a percentage of body area), and depth of the burn was recorded.

The routine use of burn charts and drawings allowed assessment of burn patterns. In the history, 
attention was paid to the explanation that the parents gave of the burn and any delay or failure to present for medical treatment. Unusual responses in the parent or child were noted.

\section{Results}

There was the usual excess of boys in both groups, more pronounced in the cases of abuse where boys outnumbered girls by two to one. Half the accidents occurred in the second year of life. In the cases of abuse the peak was in the third year with more older toddlers than is usually found in other forms of physical abuse, the oldest child being aged 8 .

History in the cases of abuse. (Table 1) The history is important in suggesting abuse. In eight cases the burn was unexplained, and in a further three the parents denied that the lesion was a burn and persisted in providing unreasonable alternative explanations. In 22 cases the parents denied witnessing the alleged accident but offered a speculative account of what had happened. Accurate numbers of unwitnessed genuine accidents were not available but in one prospective study $10 \%$ were found ${ }^{6}$ In three cases the parent blamed a child or sibling for inflicting the burn, while six children gave a story that contradicted the parents' account, implying that the injury had been deliberately inflicted. Inappropriate delay or failure to seek medical attention was found in 20 cases of abuse, but delay was recorded in only seven of the accidents. The perpetrator of the abuse was identified in 21 children, being the father in five, the mother in 10 , the male cohabitee of the mother in five, and the male 'lodger' in one.

Types of burns and causes. (Table 2). Of the 197 burns studied, the cause or type of burn was known in 186. Of these, 142 were scalds from hot water, of which 134 were from accidents and eight from abuse. There were 115 scalds from accidentally spilled hot drinks, water, or food in cups, kettles, or pans and three from deliberate abuse by similar agents. Cases of abuse included one with severe and poorly explained facial scalds from hot food in an 8 month old baby, who was also failing to thrive. In a

Table 1 Presenting history in cases of abuse

\begin{tabular}{lc}
\hline Delay/avoidance of treatment & 20 \\
Incident not witnessed & 22 \\
No explanation & 8 \\
Not a burn & 3 \\
Child or sibling blamed & 3 \\
Immediate confession of abuse & 3 \\
\hline
\end{tabular}

Table 2 Types of burns and their causes

\begin{tabular}{lcc}
\hline & $\begin{array}{l}\text { Accidents } \\
(n=165)\end{array}$ & $\begin{array}{l}\text { Abuse } \\
(n=32)\end{array}$ \\
\hline Scalds: & 134 & 8 \\
$\quad$ Total & 112 & 3 \\
Drinks, food, pans, kettles & 22 & 5 \\
Baths, sinks, domestic hot water & 12 & 14 \\
Contact burns: & 9 & 7 \\
$\quad$ Total & 0 & 3 \\
Room heaters: & 3 & 4 \\
Cigarettes & 17 & 1 \\
Tools, appliances, irons & 17 & 0 \\
Other: & 0 & 1 \\
Total & 2 & 9 \\
Fat, caustic, flame, electrical & & \\
Radiant (electric fire), molten plastic & Unknown &
\end{tabular}

second case the mother told us that her 3 year old child sustained scattered scalds from coffee thrown by the father who had been drinking, and in a third case a 21 month old boy sustained full thickness scalds to his hand and wrist after forced immersion in a kettle of boiling water.

Scalds resulting from incidents involving domestic tap water in baths, sinks, or from hoses occurred in 27 children, of which 22 were accidents and five were cases of abuse. Four abused children were scalded when forcibly immersed in a bath of hot water (Fig. 1), three with buttocks involved and two with additional scalds to both feet. A fifth child sustained scalds when his hands were forcibly held under the hot tap.

Dry contact burns from touching a hot object were found in 26, of which 12 were accidents and 14 cases of abuse. This study included no cases of accidental cigarette burns as these would be unlikely to be seen at hospital, but three children were abused by cigarettes. In one child the cigarette burn was followed a month later by an unexplained contact burn of the hand. A second 4 year old with a deep circular cigarette burn in the palm of his hand said that his father had been responsible, and another of 10 months sustained three cigarette burns to his legs.

Room heaters (such as electric bar and gas fires) were responsible for burns in 16 , of which nine were accidents and seven cases of abuse. There were seven accidental hand burns, and all involved fingers and palms. One child sat on a heater (unwitnessed) and one fell against one, burning her arm. In the cases of abuse the burns from heaters involved hands in five (backs of hands and wrists in every case) and a foot and a leg in one each.

No burns from water filled central heating radiators were identified in accident cases, although in one case of abuse the child's feet may have been 


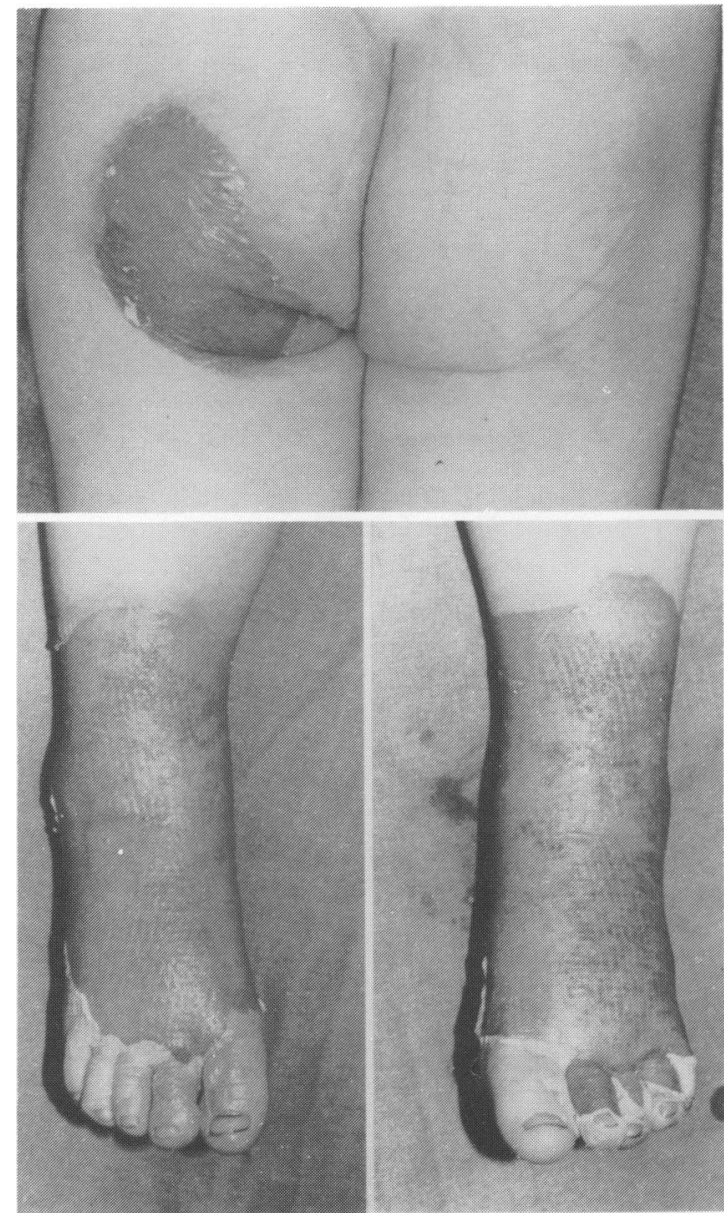

Fig. 1 Boy of 30 months with symmetrical 'stocking' scalds to both feet, full thickness in part, and superficial scald to buttock with intervening areas unaffected. History of unwitnessed bath accident but actually forced immersion, which was later admitted.

held against such an appliance (Fig. 2). Contact burns involving other appliances were responsible for burns in seven, of which three were accidents and four cases of abuse. Individual accidents included finger burns from a hot light bulb, palm and finger burns from grasping an iron, and an unusually deep burn to the back of the hand in a 10 month old baby who crawled against an iron on the floor. The parents delayed for 48 hours before seeking medical help but surprisingly no question of abuse was considered. Abuse from contact with hot implements including three children with leg burns, two from an iron and one from curling tongs, and a fourth with iron burns to the back of the hand.

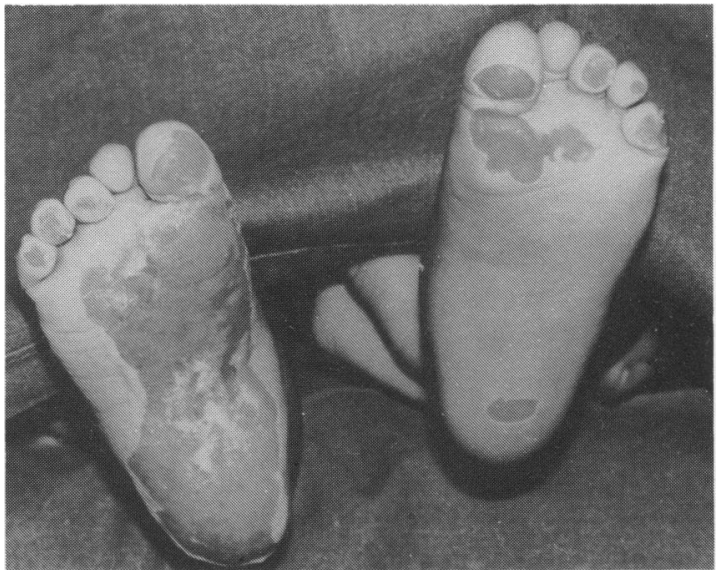

Fig. 2 Inflicted contact burns of the feet in a 9 month old baby. The water filled radiator was too cool and too far up the wall to account for the child injuring himself by crawling against it.

There were 17 burns from other agents, including naked flames, molten plastic, electrical currents, caustic substancess, and hot fat. All followed accidents.

Site. Important differences in the incidence of burns in a particular site (expressed as the percentage of children in each group with burns involving the particular named site) are shown in Figure 3. In accidents the head and neck, anterior trunk, and arms are most often affected, reflecting the areas usually involved in the common pour scald injury. In our cases of abuse the hands, legs, feet, and buttocks were the predominant sites.

Hand burns in 40 children ( 29 accidents and 11 cases of abuse) involved the dorsum of the hand in 12 (four accidents and eight cases of abuse) (Fig. 4). The more usual site for accidental hand burns was the palm and anterior surface of the fingers, as might be expected from the usual way in which children grasp and manipulate objects. Of 21 children with burns of the buttocks and perineum, 14 followed accidents and seven cases of abuse. These included six children with isolated burns to the buttocks or perineum (one accident and five cases of abuse).

Size and depth. In Table 3 the area of skin involved by the burn, expressed as a percentage of the total body surface area, was estimated and recorded for most of the accidents and in all the cases of abuse. Burns involving $5 \%$ or more of body surface area were more common after accidents (96) than abuse 


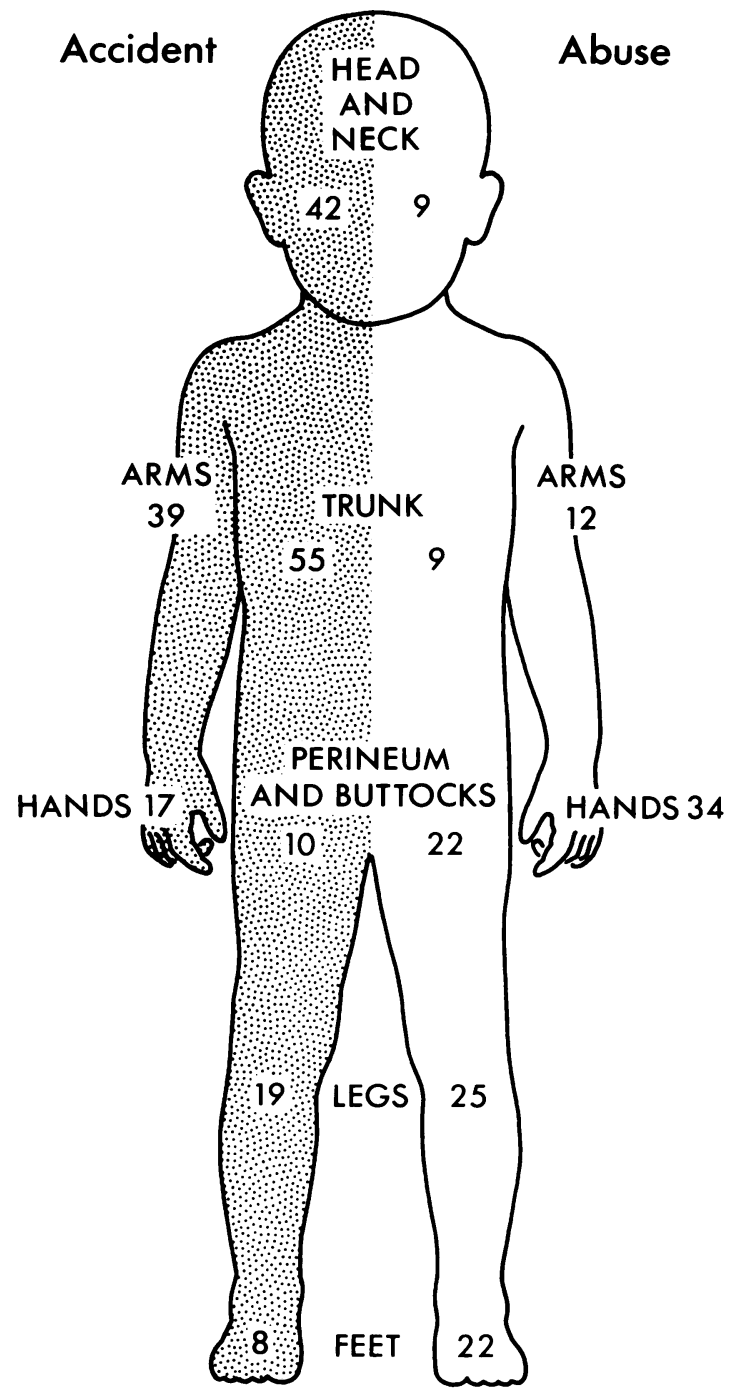

Fig. 3 Incidence of burns in particular sites expressed as the percentage in each group (accident and abuse) with burns involving that site.

(five). There were no deaths after abuse and only one after an accident, although very severe burn cases in Leeds are usually admitted to a specialised unit in another hospital and are not included in this study.

\section{Discussion}

The recognition that burns or scalds have been intentionally inflicted is difficult. It calls for awareness that such injuries occur and knowledge of the clinical picture of this form of abuse.

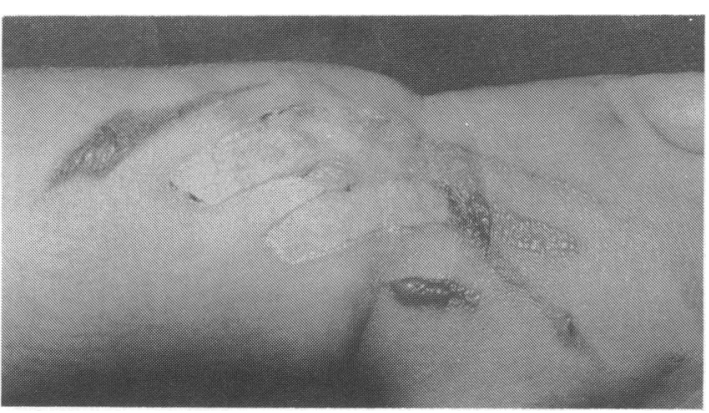

Fig. 4 Hand of an 11 month old girl allegedly brushed against fire by an older sibling. Superficial grid burn of back of hand and wrist. Child's mother later admitted herself to inflicting this single injury.

Table 3 Extent and thickness of burns in abuse and accident. Values are No (\%) of children

\begin{tabular}{llc}
\hline & $\begin{array}{l}\text { Accidents } \\
(n=165)\end{array}$ & $\begin{array}{l}\text { Abuse } \\
(n=32)\end{array}$ \\
\hline $\begin{array}{l}\text { Extent (\% of body area): } \\
\quad<5 \%\end{array}$ & $48(29)$ & $27(84)$ \\
$5 \%-10 \%$ & $82(50)$ & $4(13)$ \\
$>10 \%$ & $14(8)$ & $1(3)$ \\
$\quad \begin{array}{l}\text { Insufficient information } \\
\text { Severity: }\end{array}$ & $21(13)$ & $0(0)$ \\
$\quad \begin{array}{l}\text { Entirely superficial } \\
\text { With decper area (includes full } \\
\text { thickness and partial thickness) }\end{array}$ & $126(76)$ & $23(72)$ \\
\hline
\end{tabular}

From the results of this study, features that suggest abuse in burns and scalds in young children include:

(1) Repeated burns, or burns occurring in a pattern of repeated injury.

(2) Injury incompatible with history.

(3) Inappropriate parental response: delay in seeking treatment, blaming the child or sibling, denial that the lesion is a burn.

(4) Changes in the history; absence of eye witness accounts.

(5) Site: hand, especially back and wrist, buttocks, and feet and legs.

(6) Type: contact burns in unusual sites, showing clear outline of object, or scalds with clear cut edges, glove and stocking distribution.

There are few entirely specific injuries that on their own allow us to diagnose abuse. Even cigarette burns arise accidentally from brushed contact, although the appearances are then of a more superficial, eccentrically shaped mark. A burn may be the only injury in cases of abuse, and the presence of other additional non-accidental injuries 
does not provide certain confirmation that a burn was deliberately inflicted, although it is obviously suggestive.

These difficulties of diagnosis may in part be reflected in the varying incidence of non-accidental burns reported in earlier studies. These ranged from $1.7 \%$ to $16 \%{ }^{1-5}$ of all childhood burns admitted to hospital, the lower figure reflecting British experience. Burns have accounted for $6-17 \%^{78}$ of all types of injuries in abused children, although in this study only $4 \%$ of children seen in Leeds with nonaccidental injury during this period had burns, suggesting that we have been cautious in making the diagnosis.

American studies uniformly report non-accidental burns to be severe, more often scalds than burns and associated with appreciable mortality. ${ }^{3-57}$ The present study, while conflicting with those conclusions, broadly agrees with an earlier British study that reported injuries to be more often burns than scalds, usually of minor extent (less than $5 \%$ body surface area), and with no deaths. ${ }^{2}$

It may be that inflicted burns in this country follow a different pattern from those seen in America or that we are less proficient in recognising the more severe cases of abuse. Other characteristics of non-accidental burns where these results are in agreement with other studies include the greater mean age (usually between 2 and 3 years) than generally found in physically abused children and the presentation with inexplicable delay or avoidance of medical attention, an inconsistent, vague or absent history, and unwitnessed incidents. A pattern of repeated burns, as found in two children, has also been described.

Examples of specific patterns of burns described in earlier studies ${ }^{7}$ were also found. These included forced immersion scalds (also known as tub burns), which occur when a child is forcibly immersed, for example, into a bath of hot water, splash or thrown scalds, and grid burns.

Important sites include the perineum and buttocks, involved in $92 \%$ of cases in one study, ${ }^{5}$ and $22 \%$ in this. The back of the hand seems to be an important site not previously mentioned. The adult may hold the child's hand against a hot surface by the fingers or arm as was admitted in four cases. In another four cases of abuse the leg was burned by an implement or tool such as an iron, although this was not found in accidents.

Investigation of abuse. This involved a coordinated input from a team, including surgeon, paediatrician, nurse, social worker, and police officer. A carefully taken and recorded history as soon after the admission to hospital as possible was linked to a detailed assessment of the home environment and the social circumstances of the family.

Behavioural characteristics of the children and their interaction with parents and staff provided additional valuable information. On several occasions the quiet and frightened child on admission blossomed into the rebellious, hyperactive, and disobedient toddler whose behaviour could well have triggered the abuse. Visits to the home helped in understanding and supporting parents and in the practical assessment of the circumstances of the injury. Heating engineers were occasionally involved to assess, for example, whether the water temperature in a bath sufficient to scald the child could be achieved in the way that had been claimed. Another useful forensic aid was photography of the burn, showing the pattern in relation to different postures in which the child might have been held.

Conclusions. Differences exist between burns and scalds that result from accidents and those that follow deliberate injury or abuse. Careful consideration of the history coupled to an analysis of the pattern and site of the burn or scald injury should enable non-accidental burns to be recognised.

Characteristic features of abuse have been described from an analysis of 32 burns and scalds in 30 children. It is likely that greater numbers of cases will come to light with increasing awareness by doctors who care for burned children.

I thank the plastic surgeons at St James's (University) Hospital for support with this study, Miss Lynne Hawkins for secretarial help, and Dr Michael Buchanan and Professor Roy Meadow for helpful advice and criticism. Dr Jane Wynne and Dr Nicholas Wild provided additional case material and the Departments of Medical Illustration at Leeds General Infirmary and St James's Hospital the photographic material.

\section{References}

'Raine PAM, Azmy A. A review of thermal injuries in young children. J Pediatr Surg 1983;18:21-6.

${ }^{2}$ Keen JH, Lendrum J, Wolman B. Inflicted burns and scalds in children. Br Med J 1975;i:268-9.

${ }^{3}$ Hight DW, Bakalar HR, Lloyd JR. Inflicted burns in children. Recognition and treatment. JAMA 1979;242:517-20.

${ }^{4}$ Phillips PS, Pickrell E, Morse TS. Intentional burning. A severe form of child abuse. J Amer Coll Emerg Phys 1974;3:388-90.

s Stone ND, Rinaldo L, Humphrey CR, Brown RH. Child abuse by burning. Surg Clin North Am 1970;50:1419-24.

${ }^{6}$ Martin HL. Antecedents of burns and scalds in children. $\mathrm{Br} \mathrm{J}$ Med Psychol 1970;43:39-47.

${ }^{7}$ Lenoski EF, Hunter KA. Specific patterns of inflicted burn injuries. J Trauma 1977;17:842-6.

${ }^{8}$ Smith SM, Hanson R. Battered children-a medical and psychological study. Br Med J 1974;iii:666-70.

Correspondence to Dr C J Hobbs, Department of Paediatrics and Child Health, St James's (University) Hospital, Beckett Street, Leeds LS9 7TF, England.

Received 13 January 1986 